\title{
APPLICATION OF TWO NON-COMMERCIAL PROGRAMMES TO IMAGE PROCESSING AND EXTRACTION OF SELECTED FEATURES OCCURRING IN MATERIAL MICROSTRUCTURE
}

\author{
${ }^{1}$ Agnieszka SZCZOTOK, ${ }^{2}$ Dariusz KARPISZ \\ ${ }^{1}$ Silesian University of Technology, Katowice, Poland, EU, agnieszka.szczotok@polsl.pl \\ ${ }^{2}$ Cracow University of Technology, Cracow, Poland, EU, dkarpisz@pk.edu.pl
}

https://doi.org/10.37904/metal.2019.971

\begin{abstract}
Metallography is the study of the microstructure of all types of metallic alloys. By extension, the same principles can be applied to the characterization of any material. Metallographic analysis of a materials microstructure helps us first of all in identifying of composition and thermomechanical history of a material determining if the material has been processed correctly and is therefore a critical step for determining product reliability and for determining why a material failed. Nowadays many non-commercial computer-aided programmes are being developed and applied to metallographic investigations. The paper presents selected examples of application of two non-commercial programmes to metallographic investigations of $\mathrm{Y}^{\prime}$ phase precipitates in Ni-based superalloy CMSX-4. The aim of the research is to demonstrate some possibilities of the programmes and to discuss some aspects of image selection for the research, image preprocessing, and morphological and mathematical transformations, which can effect quantitative results of metallographic analysis.
\end{abstract}

Keywords: Metallographic analysis, Ni-based superalloy, non-commercial programme, image analysis, microstructure

\section{INTRODUCTION}

The understanding of the relationship between the microstructure and macroscopic properties of materials plays a key role in the development and manufacture of materials and is the main aim of metallography according to the old but still vital definition created by Cochrane [1]. A broader look at the origins of metallography can provide information about a work of Henry Clifton Sorby. His particular interests in geology, metallurgy, and marine biology brought important contributions to the mentioned areas of knowledge through his inkling of importance of applying thin sections of rocks and metals and microscopic examination techniques. His pioneering work in Sheffield (UK) highlighted bond between the microstructure and macroscopic properties. Many important macroscopic properties of metallic materials are highly sensitive to the microstructure. By examining and quantifying microstructure of a material, its performance can be better understood. The microstructures of metals and alloys are determined by composition, solidification processes, and thermomechanical treatment. Therefore, some variables of these processes determine the response of metals and alloys to service environment. Because of the relationships between structure and properties, metallographic characterization is used in materials specification, quality control, quality assurance, process control, and failure analysis if needed [2]. Microscopic image analysis is a rapidly expanding field. Since most of images are acquired through microscopy, procedures and methods for image analysis present some specifics. Together with new developments in microscopy technology, digital registration of images and the computer-aided programmes for image (pre)processing and analysis, metallography has become an irreplaceable tool for the advancement of science and industry over the last hundred years. In the last decades important advances in digital imaging and analysis systems have been noticed. More recent attention has focused on the provision of image analysis programmes dedicated to image (pre)processing in a specific area: medicine, biology, geology, materials science, etc., allowing quantitative measurements to be acquired quickly and efficiently. Image analysis is a computer-based process of extracting quantitative information from images. The process begins with the input of an image and ends with the output of numerical data. This paper will 
focus on two selected image analysis programmes with a potential in analysis of metals and alloys. The image preprocessing, segmentation and feature extraction were presented in the case of both programmes for nickelbased superalloy, especially $y^{\prime}$ phase precipitates. There are many available on the market computer-aided image analysis programmes. Some of them are commercial and others non-commercial. The selection and application of image analysis programmes is mainly the result of: friendly usage, programme abilities, accessible functions of image preprocessing/ segmentation/ feature extraction/ measurement, free plugins and macro recording feature.

\section{METHOD}

The important step in metallographic analysis is to select a sample that is representative of the material to be evaluated and to correctly prepare a metallographic specimen. Some previous studies have reported the preparation of superalloys for microstructural examination [3-7]. The essential issue in that point is to understand that not only sectioning, mounting, grinding and polishing during superalloy specimen preparation are fundamental but above all, process of etching to reveal the microstructure of a material. Metallographic etching is an electrochemical technique used to highlight features of materials at microscopic levels. Various etchants attack at different rates areas of different crystal orientation, crystalline imperfections, or different composition. Because the aim of the study is to present application of two selected computer-aided programmes for image analysis to enable comparing between them the same sample of material from nickelbased superalloy were chosen to image processing and extraction of the particles of the main strenghtening Y' phase. Phases are defined as physically homogenous and distinct constituents of the material. Phase analysis can be characterized and measured using area or volume fraction measurements per ASTM E562 (Standard Test Method for Determining vol. Fraction by Systematic Manual Point Count) or ASTM E1245 (Standard Practice for Determining the Inclusion or Second Phase Constituent Content of Metals by Automatic Image Analysis). Quantitative analysis methodologies are traditionally based on the Cavalieri's principle $[8,9]$.

\subsection{ImageJ programme}

The ImageJ is Java-based imaging program. Information about its first version one can find in 1997. Essential is that the programme is in the public domain (its source code is openly available and its use is licence-free) and what is more runs on any operating system The program is virtually limitless because of the availability of user-written macros and plug-ins (external programs, mostly written in the Java language, that offer image processing capabilities that do not exist in core capabilities of ImageJ). ImageJ can be used to acquire images directly from scanners, cameras and other video sources. The program supports all common image manipulations, including reading and writing of image files, and operations on individual pixels, image regions, whole images and volumes are ordered sequences of images that can be operated upon as a whole. It can perform basic operations such as convolution, edge detection, Fourier transform, histogram and particle analyses (including sophisticated statistical processing of groups of particles), editing and color manipulation; and more sophisticated operations such as dilation, erosion and closing of structures, and mathematical operations on sets of images, such as multiplication, exclusive or, and division. In addition, visualization operations, including color space conversions - for example, converting from RGB to Hue Saturation Intensity color space, two- and three-dimensional plotting - and surface and volume rendering, are supported [10-12].

\subsection{Gwyddion programme}

Gwyddion is primarily intended as a data visualization and processing tool for the analysis of height fields obtained by scanning probe microscopy techniques (AFM, MFM, STM, SNOM/NSOM) and support a lot of SPM data formats. However, it can be used for general height field and (greyscale) image processing, that is why it can be applied for general image and 2D data analysis. It contains all standard functions like: levelling, geometrical transforms, statistical characterisation, grain detection, data correction, FFT filtering, etc. 
Gwyddion is free and Open Source software, covered by GNU General Public License. Thanks to being free software, it provides the source code to developers and users, which makes easier both verification of its data processing algorithms and further program improvements. Gwyddion works on GNU/Linux, Microsoft Windows, Mac OS X and FreeBSD operating systems on common architectures [13,14].

\section{MATERIAL}

The material selected for the investigation is CMSX-4 single crystal Ni-based superalloy as-cast state. CMSX4 is a second generation, Re-bearing nickel-base $S X$ superalloy, which has been extensively investigated and documented in the literature [15-17]. The nominal chemistry (in wt\%) is $9.0 \mathrm{Co}, 6.5 \mathrm{Cr}, 6.0 \mathrm{~W}, 5.6 \mathrm{Al}, 1.0$ $\mathrm{Ti}, 6.5 \mathrm{Ta}, 0.6 \mathrm{Mo}, 3.0 \mathrm{Re}, 0.1 \mathrm{Hf}$, and a Ni balance. For simplicity the traditional well known microarea from a dendrite core with cubic-shaped $y^{\prime}$ phase precipitates were selected (Figure 1).

\section{RESULTS}

The first example of extraction of $y^{\prime}$ phase precipitates presented in Figure 2 is a result of simple initial grey image processing provided by ImageJ programme. Purposefully, the image was kept without any manual correction to show the importance of etching and contrast in image processing and in extracting of the analyzed precipitates. Without manual correction the programme has drawn out more than really $Y^{\prime}$ phase

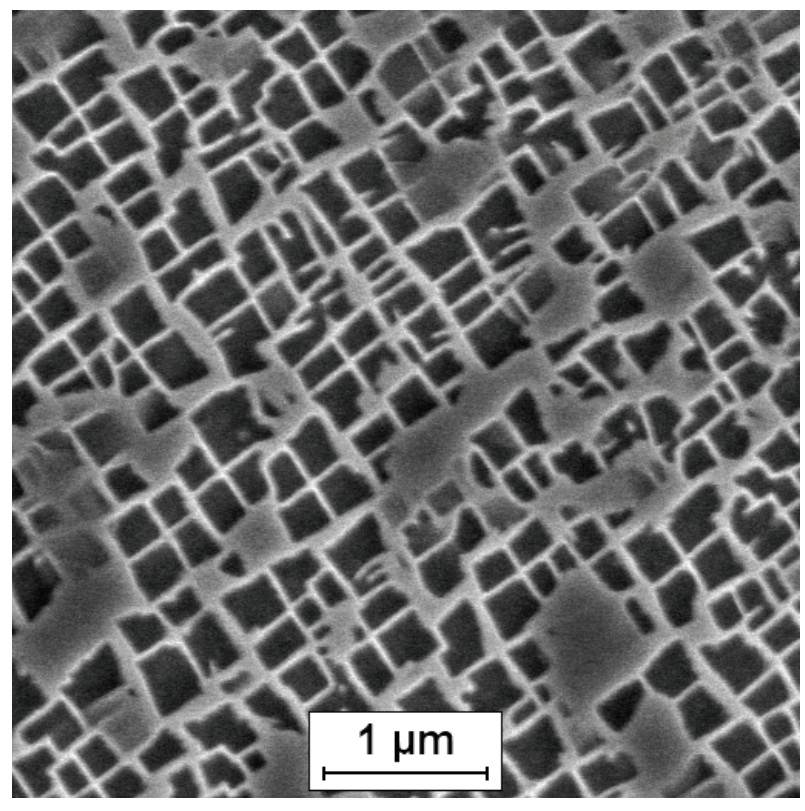

Figure 1 Typical microstructure of CMSX-4 superalloy with $y^{\prime}$ phase precipitates (SEM, $\mathrm{SE})$ precipitates encompass. As a consequence, on the basis of the image presented in Figure 2 the estimation of the volume fraction of the precipitates was carried out. The value was $55.3 \%$.
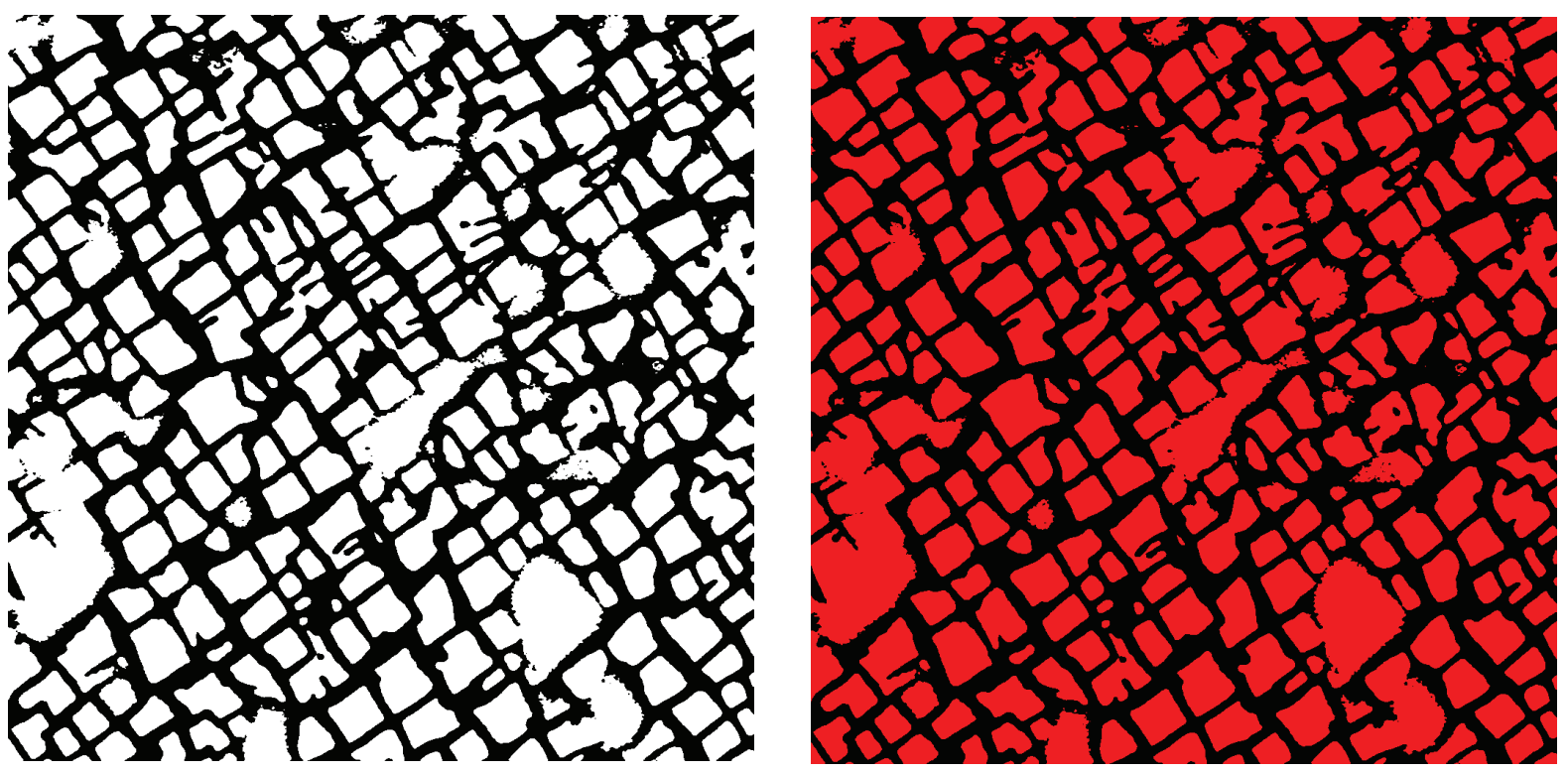

Figure 2 Results of processing of the image and extraction of $\mathrm{y}^{\prime}$ phase precipitates after application of ImageJ without any manual correction 
Afterwards, the same precipitates (Figure 1) have been evaluated by applying Gwyddion programme. The selected results of the image processing and extraction of the $y^{\prime}$ phase precipitates in that case are offered in Figure 3. The value of the volume fraction of the precipitates was assessed at $52.54 \%$. The value is closer to getting at the truth as a consequence of reducing of extraction of areas in the image which were not the $Y^{\prime}$ phase precipitates. To be sure that measurements of the extracted $y^{\prime}$ phase precipitates were held in the same conditions both measurements (for the extraction from ImageJ and Gwyddion) were performed using the same Met-llo programme.
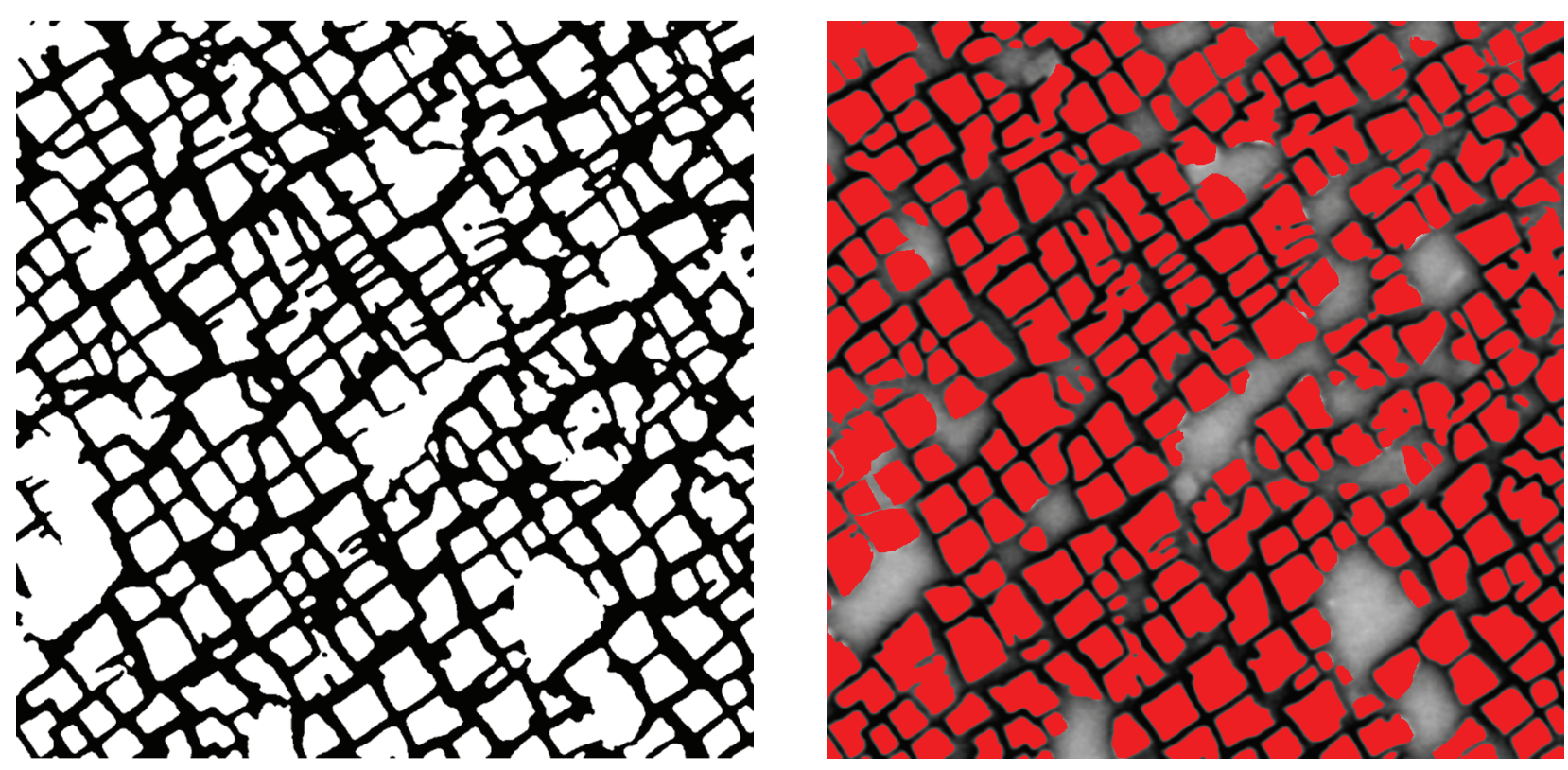

Figure 3 Results of processing of the image and extraction of $y^{\prime}$ phase precipitates after application of Gwyddion with manual correction

\section{CONCLUSION}

The manual quantitative metallography is in many cases difficult, tedious and time-consuming especially when the microstructure is complicated or of a fine scale, like in the case of the presented y' phase precipitates. Image analysis software and algorithms to image processing can be expensive to buy. For this reason noncommercial programmes for image analysis could be non-substitutable. The presented examples of application of non-commercial programmes for image analysis confirm that there are useful and free tools for image analysis of material microstructure. Any software requires training for optimal use and accurate results, especially automated image analysis. Very often beginning users do not pay enough attention to the results of too much or too less extracting features from the analyzed image. As a result it can be obtained over/underestimated result of the measurement of those features. The presented examples of extraction of $\mathrm{y}^{\prime}$ phase precipitates have shown that when used improperly, image analysis can produce erroneous results. As the techniques used in image analysis are highly dependent on computer processing, many of these errors can be introduced inadvertently, with profound results. The automatic measurement of an image analyzer can give inaccurate data if for example the microstructure has a bad contrast or the analyzed features have a discontinuous outline. The paper assists a scientist who has little or no previous experience with image analytic methodologies to focus their attention on the essential steps that should be carried out in the quantitative analysis of the material. In further investigation, some more complex statistical [18], fuzzy [19] and Monte Carlo [20-21] analysis should be employed to assess data-driven uncertainty estimation. 


\section{REFERENCES}

[1] COCHRAN, F.L. Preface. Metallography. 1968. vol. 1, no. 1, pp. vii-viii.

[2] LOUTHAN, M.R. Jr. Optical Metallography. In: WHAN R.E., ed. ASM Handbook, vol. 10: Materials Characterizations. ASM International, 1986, pp. 299-308.

[3] VANDER VOORT, George F., MANILOVA, Elena P. and LUCAS, Gabriel M. Metallographic techniques for superalloys. Microscopy and Microanalysis. 2004. vol. 10, no. S02, pp. 690-691.

[4] ZIPPERIAN, Donald C. Metallographic Handbook. PACE Technologies. Tucson Arizona USA, 2011. p. 256.

[5] BUEHLER Ltd. Buehler Sum-met. The science behind materials preparation. The Argus Press, Niles, Illinois, USA, 2007, p. 49.

[6] VANDER VOORT, George F. Metallography of superalloys. Industrial Heating. 2003. vol. 70, pp. 40-43.

[7] SZCZOTOK, Agnieszka. Metallographic study of the casting made from CMSX-6 SC nickel-based superalloy. Archives of Metallurgy and Materials. 2017. vol. 62, no. 2, pp. 581-586.

[8] DEHOFF, Robert T., Quantitative serial sectioning analysis: preview. Journal of Microscopy. 1983. vol. 131, pp. 259-263.

[9] UNDERWOOD, E.E. Stereology, or the quantitative evaluation of microstructures. Journal of Microscopy. 1969. vol. 89, no. 2, pp. 161-180.

[10] ABRÀMOFF, Michael D., MAGALHÃES, Paulo J. and RAM, Sunanda J. Image processing with ImageJ. Biophotonics International. 2004. vol. 11, no. 7, pp. 36-42.

[11] FERREIRA, Tiago, RASBAND, Wayne ImageJ User Guide IJ 1.46r. 2012. [viewed 2019-05-05]. Available from: https://imagej.nih.gov/ii/docs/guide/user-guide.pdf

[12] PASCAU, Javier and PÉREZ, José M.M. Image processing with ImageJ. PACKT Publishing, 2013.

[13] SOURCE FORGE. Gwyddion. [viewed 2019-05-05]. Available from: http://gwyddion.net/

[14] NEČAS, David and KLAPETEK, Petr. Gwyddion: an open-source software for SPM data analysis. Central European Journal of Physics. 2012. vol. 10, pp. 181-188.

[15] BURKHOLDER, P. S., THOMAS, M.C., FRASIER, D.J., WHETSTONE, J.R., HARRIS, K., SIKKENGA, S.L. and ERIDON, J.M. Allison Engine Testing CMSX-4 Single Crystal Blades and Vanes. In: Proceedings of 3rd International Charles Parsons Turbine Conference. London, UK. IOM, 1995.

[16] FULLAGAR, K.P.L., BROOMFIELD, R. W., HULANDS, M., HARRIS, K., ERICKSON, G.L., and SIKKENGA, S.L. Aero Engine Test Experience with CMSX-4 Alloy Single Crystal Turbine Blades. Transactions of the ASME. 1996. vol. 118, pp. 380-388.

[17] THOMAS, M.C., HELMINK, R.C., FRASIER, D.J., WHETSTONE, J.R., HARRIS, K., ERICKSON, G.L., SIKKENGA, S.L., and ERIDON J. M. Allison Manufacturing, Property and Turbine Engine Performance of CMSX-4 Single Crystal Airfoils. In: COUTSOURADIS D., DAVIDSON J.H., EWALD J., GREENFIELD P., KHAN T., MALIK M., MEADOWCROFT D.B., REGIS V., SCARLIN R.B., SCHUBERT F., THORNTON D.V. eds. Conference Materials for Advanced Power Engineering 1994, Proceedings of a conference COST 501, Liège, Belgium, 1994. Kluwer Academic Publishers, Dordrecht/Boston/London, pp. 1075-1098.

[18] PIETRASZEK, J. and GOROSHKO, A. The heuristic approach to the selection of experimental design, model and valid pre-processing transformation of DoE outcome. Adv. Mat. Res.-Switz. 2014, vol. 874, pp.145-149.

[19] PIETRASZEK, J., KOLOMYCKI, M., SZCZOTOK, A. and DWORNICKA, R., 2016. The fuzzy approach to assessment of ANOVA results. In ICCCI 2016: Conf. on Comp. Collective Intell. Springer, pp. 260-268.

[20] SKRZYPCZAK-PIETRASZEK, E., REISS, K., ZMUDZKI, P. and PIETRASZEK, J. Enhanced accumulation of harpagide and 8-O-acetyl-harpagide in Melittis melissophyllum L. agitated shoot cultures analyzed by UPLCMS/MS. PLOS ONE 2018, vol.13, e0202556.

[21] PIETRASZEK, J., RADEK, N., SCENDO, M., STASZEWSKA-SAMSON, K. and OSOCHA, P. Estimation of the quantitative uncertainty for the corrosion potential and corrosion current density. In METAL 2018: 27th Int. Conf. Metallurgy and Materials. Ostrava: TANGER, 2018, pp. 1204-1209. 